\title{
SIXTEEN ALBERTA BAT RECORDS, 1971-1974
}

by EDGAR T. JONES*

During the course of bird banding operations in various parts of Alberta, some rather interesting bat records have come to light. Using the mist net technique, for which an endorsed permit is required, invariably a number of bats are caught but most of them chew their way out unless removed almost immediately after contact. The following are a few interesting records, 10 of which were banded by the writer, the bands being supplied by Hugh C. Smith of the Alberta Provincial Museum and Archives:

Hoary Bat: August 23, 1972. Single adult female apparently travelling with two young, both of which chewed their way out within 2 feet of the female. H. C. Smith banded this bat and the record was filmed and recorded by the writer. Caught at my regular banding station on the south side of Edmonton. Wingspread - 16"; length - 5-1/2"; weight - 33.2 grams.

August 3, 1974. Immature female caught and banded by the writer at the same banding station within 30 feet of 1972 catch. Wingspread - 16-1/2"; weight -45.5 grams.

August 20, 1974. Adult caught and banded by writer in Red Deer Valley near Jenner.

Silver-Haired Bat: Sept. 5, 1971. Caught at Edmonton location.

August 21, 1972. Edmonton, banding location.

August 26, 1973. Red Deer Valley near Jenner.

*6115 - 141st Street, Edmonton, Alberta. T6H 4 A6.

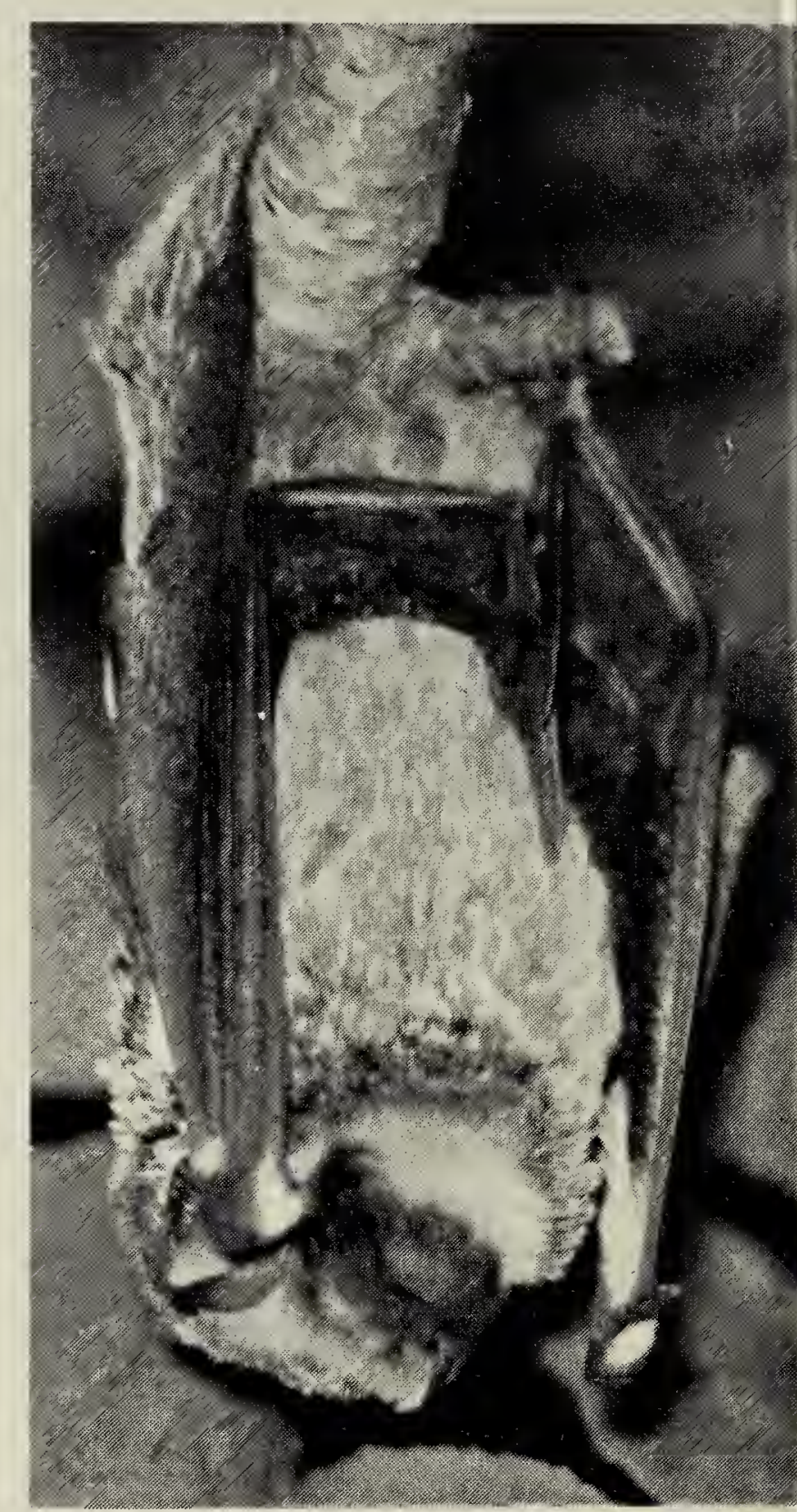

Edgar T. Jonc

Hoary Bat hanging from branch

Big Brown Bat: August 20, 1974. Singl adult caught and released near Jenner presumably on migration.

Say's Masked Bat: Individuals caugh as follows:

May 18, 1973. Near Munson, on Red Deer Valley.

June 3, 1973. Near Jenner. Two caught and released. 


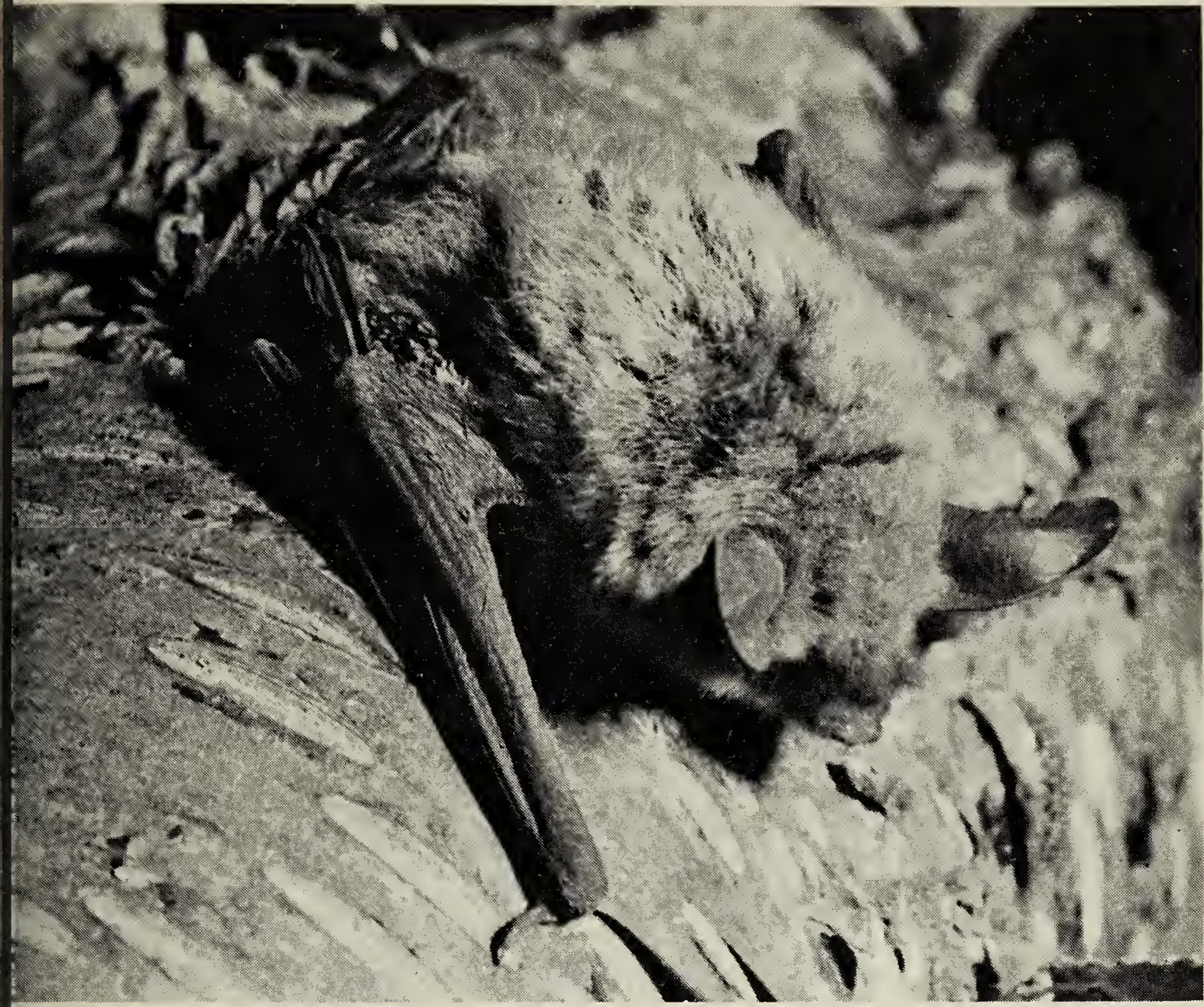

Say’s Masked Bat on tall trunk

Edgar T. Jones

June 6, 1973. Near Jenner. Single caught and released.

August 25, 1973. Near Jenner. Two caught, banded and released. August 13, 1974. Jenner. Single caught, banded and released. August 14, 1974. Jenner. Four caught, three banded. August 15, 1974. Jenner. Two banded and released.

August 16, 1974. Jenner. Single banded and released.

August 20, 1974. Jenner. Two banded of three caught.
Mammals of Alberta by Dr. J. Dewey Soper, 1964, includes only three records of this bat in the Province. Since that time one or two other records have been reported by the Provincial Museum staff, not including those listed above. It appears that this bat is much more widely distributed in southeastern Alberta than previously indicated.

When the last individual of a race of living things breathes no more, another heaven and another earth must pass before such a one can be again.

William Beebe 